
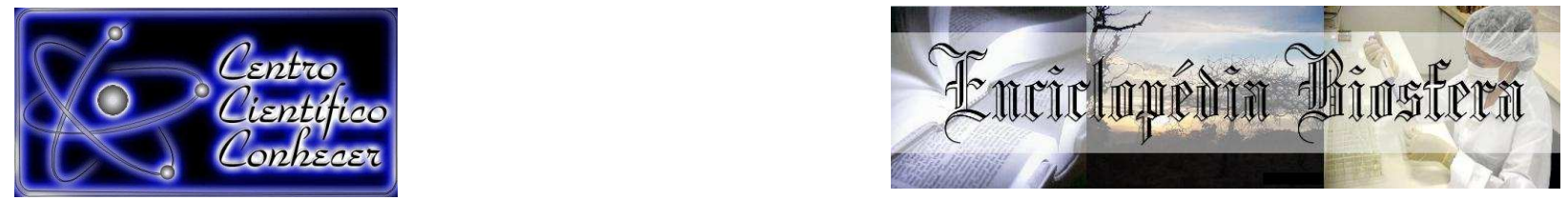

\title{
ESTRUTURAS SECRETORAS EM FOLHAS DE Clusia fockeana MIQ. E Clusia hoffmannseggiana SCHLTDL. (CLUSIACEAE): DISTRIBUIÇÃO E ANATOMIA
}

\begin{abstract}
Marleide de Sousa Chaves Rêgo ${ }^{1}$; Tatiani Yuriko Souza Kikuchi ${ }^{2}$
${ }^{1}$ Universidade Estadual do Piauí, Campus Heróis do Genipapo, Av. Santo Antônio s/n, 64280-000, Bairro São Luis, Campo Maior, Piauí, Brasil.

(marleide.chaves@yahoo.com.br).

${ }^{2}$ Laboratório de Anatomia Vegetal, Museu Paraense Emílio Goeldi, Coordenação de Botânica, Av. Tancredo Neves, 1901, 660077-530, Terra Firme, Belém, Pará, Brasil.

Recebido em: 08/09/2015 - Aprovado em: 14/11/2015 - Publicado em: 01/12/2015

DOI: http://dx.doi.org/10.18677/Enciclopedia_Biosfera_2015_018

RESUMO

Embora Clusia fockeana Miq. e C. hoffmannseggiana Schltdl tenham eficácia comprovada no tratamento de diversas doenças, os possíveis sítios de produção das substâncias de ação terapêutica são praticamente desconhecidos. O objetivo do trabalho foi caracterizar a dinâmica de distribuição, tipos estruturais e as principais classes de compostos produzidos pelas estruturas secretoras presentes em folhas de Clusia fockeana e $C$. hoffmannseggiana, assim como descrever os estágios iniciais de desenvolvimento dos ductos secretores dessas espécies. Amostras foram coletadas na restinga do Crispim, PA, fixadas e processadas segundo técnicas usuais em microscopia de luz e eletrônica de varredura. Idioblastos, ductos e tecido paliçádico secretor são as estruturas secretoras presentes nas folhas de Clusia fockeana e $C$. hoffmannseggiana, exceto para o tecido paliçádico secretor que é exclusivo à $C$. Fockeana, e foi descrito pela primeira vez para o gênero Clusia. Tanino é a principal substância armazenada e/ou secretada pelos idioblastos e ductos. Ambas as espécies possuem ductos distintos em relação à distribuição, quantidade e diâmetro do lume. Estes são desenvolvidos no meristema fundamental do mesofilo e nervura central, através de processo esquizógeno. A distribuição das estruturas secretoras confere valor diagnóstico aos táxons analisados e contribui com dados inéditos para o melhor conhecimento das espécies em estudo e bioprospecção de seus compostos bioativos.
\end{abstract}

PALAVRAS-CHAVE: Amazônia, bioprospecção, medicinal, tecido paliçádico secretor

\section{SECRETORY STRUCTURES IN Clusia fockeana MIC. AND Clusia hoffmannseggiana SCHLTDL. (CLUSIACEAE): DISTRIBUTION AND ANATOMY}

\begin{abstract}
Although Clusia fockeana Mic. and $C$. hoffmannseggiana Schltdl has proven efficacy in the treatment of various diseases, potential sites of production of the therapeutic action of substances are unknown. The goal of this study was to characterize the dynamic of distribution, structural types and the main classes of compounds produced by the secretory structures present in leaves of Clusia fockeana and $C$.
\end{abstract}


hoffmannseggiana and to describe the early stages of development of the secretory ducts of these species. The samples were collected in the sandbank of Crispim, PA, fixed and processed according to the methods of light microscopy and electron scanning. Idioblasts, ducts and secretory palisade tissue are secretory structures present in the leaves of Clusia fockeana and C. hoffmannseggiana except for the secretory palisade tissue that is exclusive to $C$. fockeana, being first described for the Clusia genus. Tannin is the main storage medium and/or secreted by idioblasts and ducts. Both species are different in relation to the distribution, quantity and diameter lume of the ducts. These ducts develop in the meristematic tissue of the mesophyll and midrib through schizogenous process. The distribution of secretory structures provides diagnostic value to the taxa analyzed and contributes withunpublished data to the better knowledge of the species and bioprospecting their bioactive compounds. KEYWORDS: secretory palisade tissue, medicinal plant, bioprospection, Amazon.

\section{INTRODUÇÃO}

Nos últimos anos, muitas espécies de Clusiaceae têm sido objeto de várias pesquisas devido suas atividades farmacológicas (CRUZ \& TEIXEIRA, 2004) e biológicas (REYES-CHILPA \& HUERTA - REYES, 2009). Estudos químicos revelaram que as atividades biológicas nessa família incluem propriedades antioxidante, antimicrobiana (LOKVAM \& BRADDOCK, 1999; PRETTO et al., 2004; RIBEIRO et al., 2011), antibacteriana (LOKVAM et al., 2000), moluscidas (PINHEIRO et al., 2003; GASPAROTTO-JÚNIOR et al., 2005a), anti-HIV-1 (HUERTA-REYES et al., 2004), antiulcerogênica e citotóxica (NOLDIN et al., 2006), antifúngica (PEDRAZA-CHAVERRI et al., 2008), anti-inflamatória (ACUÑA et al., 2009), toxicológica (REYES-CHILPA et al., 2009), analgésica (CUI et al., 2010), antiplasmodial (MARTI et al., 2010) e anti-inflamatório tópico (OTUKI et al., 2011). Podendo-se afirmar que este grupo de plantas possui uma riquíssima fonte de novos compostos químicos, especialmente xantonas, benzofenonas e biflavonoides (FERREIRA et al., 2012).

Dentre os maiores gêneros que se destacam na família cita-se, Clusia L., com cerca de 200 espécies, com grande diversidade de hábitos, sendo frequentemente encontradas em matas litorâneas (JOLY, 1998). Além disso, as plantas desse grupo têm sido usadas na medicina popular como unguentos e tônicos no combate à hipertensão, dores no corpo, ulceras e feridas (FERNANDES, 2007).

Em Clusia foram identificadas a presença de benzofenonas poliisopreniladas nas folhas, raízes, frutos e látex de suas espécies (LOKVAM et al., 2000). Clusia fockeana Miq. e Clusia hoffmannseggiana Schltdl. são arbustos, conhecidos pelos nomes populares de "cebolinha brava e/ou cebolão", respectivamente (FONSECA et al., 2005; CARNEIRO et al., 2010). Estas plantas são utilizadas pelas populações tradicionais no tratamento de diversas doenças, devido suas propriedades diuréticas e antiermética (JARDIM et al., 2005). Entretanto, os possíveis sítios de produção das substâncias de ação terapêutica das mesmas são praticamente desconhecidos, o que evidência a importância de investir esforços para ampliar o conhecimento sobre as mesmas (RÊGO, 2012).

Segundo dados de METCALFE \& CHALK (1950) e FERREIRA et al. (2012) nas Clusiaceae esses atributos medicinais estão diretamente relacionados a tipos especiais de estruturas secretoras, especialmente ductos e cavidades, pois são eles os sítios de produção dos metabólitos secundários responsáveis por tais propriedades, sendo esta uma característica de valor taxonômico para a família. 
Adicionalmente, além de serem usadas para delimitar espécies, gêneros ou mesmo uma família inteira, as estruturas secretoras podem servir de paramentos para a utilização ou não de certas partes vegetais (METCALFE \& CHALK, 1950). Por esse prisma, no caso das espécies em estudo, regiões com maior ocorrência de estruturas secretoras, seriam as mais indicadas para serem usadas medicinalmente.

Outrossim, mostram-se relevantes para o conhecimento de sua anatomia, da natureza química do exsudato e do papel que desempenham no corpo do vegetal (LÜTTGE, 1971; THADEO et al., 2009; VILHENA-POTIGUARA et al., 2012).

Diante disso, este trabalho teve como objetivo caracterizar a dinâmica de distribuição, tipos estruturais e as principais classes de compostos produzidos pelas estruturas secretoras presentes nas folhas de Clusia fockeana e C. hoffmannseggiana, assim como descrever os estágios iniciais de desenvolvimento dos ductos secretores de ambas as espécies, a fim de ampliar tais conhecimentos e subsidiar estudos com fins farmacológicos.

\section{MATERIAL E MÉTODOS}

Amostras das folhas de Clusia fockeana e C. hoffmannseggiana foram coletadas de cinco indivíduos de cada espécie, na restinga de Crispim, município de Marapanim, estado do Pará. Parte do material botânico foi destinada à confecção de exsicatas, as quais foram identificadas pelo Dr. Volker Bittrich, especialista na família, e incorporadas como testemunha ao Herbário João Murça Pires (MG), com número de registro MG201973 e MG201972, respectivamente.

Para o estudo anatômico das estruturas secretoras amostras foram retiradas das folhas de ambas as espécies a partir do $1^{\circ}$ ao $5^{\circ}$ nós visíveis e fixadas em formol, ácido acético e álcool 70\% - FAA, por 24 horas (JOHANSEN, 1940), formalina neutra tamponada - FNT (LILLIE, 1965) e sulfato ferroso em formalina SFF, por 48 horas (JOHANSEN, 1940). Foram analisados o terço mediano do pecíolo e lâmina foliar, selecionando-se amostras das regiões da margem, intermediária e nervura central.

Parte do material foi desidratada em série de álcool butílico terciário (JOHANSEN, 1940), incluído em parafina e seccionado transversal e longitudinalmente em micrótomo rotativo Leica® RM 2245. As secções seriadas, com 14-16 $\mu \mathrm{m}$ de espessura, foram coradas com safranina e azul de astra (GERLACH, 1969) e montadas em resina sintética Permount®.

Para o estudo de microscopia eletrônica de varredura (MEV), amostras do mesofilo, pecíolo e nervura central foram fixadas em FNT e desidratadas em série etílica (JOHANSEN, 1940). Posteriormente, as amostras foram secas pelo método do ponto crítico - MTECH K850, afixadas em "stubs" com fita adesiva dupla face e metalizadas com ouro - MTECH K550. As observações e captura das imagens foram realizadas em microscópio LEO a $20 \mathrm{kV}$.

Testes microquímicos foram aplicados em secções previamente fixadas e realizados cortes à mão, utilizando cloreto férrico10\% para detecção de compostos fenólicos totais (JOHANSEN, 1940), vanilina clorídrica para tanino (MACE \& HOWELL, 1974), sudan III para lipídios (SASS, 1951), solução de Lugol para grãos de amido (JOHANSEN, 1940) e ácido clorídrico 10\% para cristais de oxalato de cálcio (CHAMBERLAIN, 1932).

As fotomicrografias foram obtidas através de microscópio Axiolab Zeiss, com câmera digital Canon Powershot A640 acoplada e as escalas projetadas nas mesmas condições ópticas. 


\section{RESULTADOS E DISCUSSÃO}

As estruturas secretoras observadas nas folhas de Clusia fockeana e $C$. hoffmannseggiana foram: idioblastos, tecido paliçádico secretor e ductos (Figuras 1A-G, 2A-J, Tabela 1). Contudo, o tecido paliçádico secretor ocorre apenas em $C$. fockeana (Figuras 1F e 2A, D-E).

Segundo CRONQUIST (1981) e STEVENS (2007) a família Clusiaceae apresenta como característica marcante nas folhas, a presença de ductos e cavidades secretores esquizógenos, próximos aos feixes vasculares ou independentemente no mesofilo, além da região medular e cortical do pecíolo; onde são elaborados e secretados diversos metabólitos secundários (METCALFE \& CHALK, 1950).

As espécies de Clusia possuem sistemas de canais produtores de látex resinoso, que variam em abundância, densidade e cor. E estas variações são observadas não só entre as espécies, mas também entre diferentes órgãos da mesma planta (ANHOLETI et al., 2015). Os idioblastos, em secção transversal, ocorrem no córtex do pecíolo (Figuras $1 A-E$ ), parênquima fundamental da nervura central (Figuras 1F-G) e mesofilo (Figuras 2A-B) de ambas as espécies analisadas.

Quanto à natureza dos exsudados, os idioblastos, apresentaram conteúdo com aspecto granuloso (Figura 1D) e denso (Figuras 1D, 2F-J). O tecido paliçádico secretor foi observado na nervura central (Figura 1F), mesofilo (Figura 2A) e margem da lâmina foliar apenas de Clusia fockeana (Figuras 2D-E).

Os ductos, em secção transversal, de modo geral, localizam-se em todos os tecidos da folha (Figuras 1A-G e 2A-J), apresentando células epiteliais com formato tabular, que variam de seis a oito (Figuras $1 \mathrm{E} \mathrm{e} 2 \mathrm{H}$ ). O formato dos lúmens é circular e de diversos calibres (Figuras1G e 2H). Em secção longitudinal, essas estruturas se apresentam alongadas nas duas espécies analisadas (Figura 2G).

Ductos secretores e idioblastos foram evidenciados no mesofilo, no parênquima cortical da nervura central e pecíolo de várias espécies de Clusia (PAULA, 1966; SCHNEIDER, 1985; FERNANDES, 2007; ROCHA et al., 2014; SILVA et al., 2014). Ambos com conteúdo fenólico, especialmente tanino.

Em Clusia hilariana Schlecht. ductos secretores foram relatados na hipoderme, sendo também reportado no parênquima subepidérmico, células com suposto compostos fenólicos, além de ductos secretores de diferentes tamanhos (SILVA et al., 2005). A presença dos ductos com compostos fenólicos, distribuídos no parênquima fundamental e associados ao sistema vascular em folhas de Calophyllum brasiliense Cambess (Clusiaceae) também foi mencionada nos estudos de GASPAROTTO-JÚNIOR (2005b). No entanto, o tecido paliçádico secretor observado em Clusia fockeana, ainda não foi registrado para nenhuma espécie estudada até o momento, sendo este o primeiro registro dessa estrutura para este táxon e gênero Clusia. 

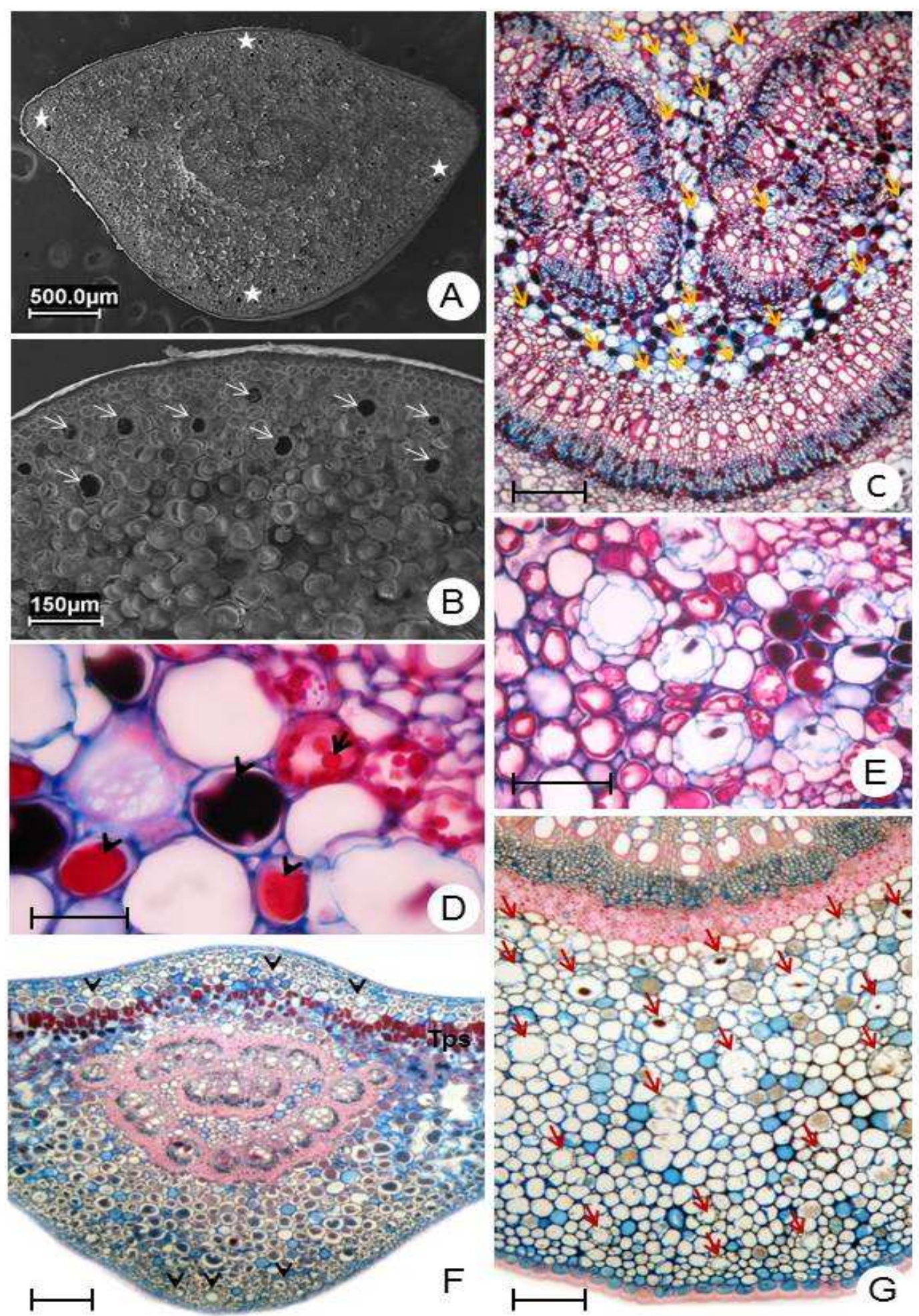

FIGURA 1. Distribuição e anatomia das estruturas secretoras observadas no pecíolo e nervura central de Clusia fockeana (A-B, F) e Clusia hoffmannseggiana (C-E, G). A. Vista geral do pecíolo, exibindo a região cortical e vascular, notar ductos próximos à epiderme (asteriscos). B. Detalhe dos ductos na periferia do pecíolo (setas). C. Idioblastos e ductos na região medular do pecíolo, notar ductos associados ao sistema vascular (setas). D: Detalhe dos idioblastos com conteúdo de aspecto denso no pecíolo (cabeça de seta) e granuloso (seta). E: Detalhe dos idioblastos e ductos na medula do pecíolo, notar abundância dos ductos. F: Visão geral da nervura central, evidenciando ductos na periferia (cabeça de seta), notar tecido paliçádico secretor e idioblastos em todos os tecidos. G: Região cortical da nervura central, evidenciando ductos de variados calibres por toda extensão (setas). Escalas: $A=500 \mu \mathrm{m} ; \mathrm{D}$ e $\mathrm{E}=20 \mu \mathrm{m} ; \mathrm{C}=50 \mu \mathrm{m} ; \mathrm{F}=200 \mu \mathrm{m} ; \mathrm{B}$ e $\mathrm{G}=150 \mu \mathrm{m}$.

ENCICLOPÉDIA BIOSFERA, Centro Científico Conhecer - Goiânia, v.11 n.22; p.2997 2015 
$\mathrm{Na}$ lâmina foliar de Clusia fockeana, os ductos foram observados encarreirados na hipoderme (Figura 2A), se estendendo até a margem (Figura 2D), além do córtex e medula do pecíolo (Figuras 1A-B) e nervura central (Figura 1F). Porém, em Clusia hoffmannseggiana, os ductos ocorrem principalmente no parênquima paliçádico e esponjoso (Figura 2B), principalmente próximo ao sistema vascular (Figuras 1C e 1E).

Já no pecíolo e na nervura central, os ductos, estão dispersos no parênquima cortical, especialmente ao redor do sistema vascular. Nessas regiões os calibres dos lúmens apresentam-se semelhantes. Já em Clusia hoffmannseggiana, estas estruturas ocorrem em todos os tecidos da lâmina foliar, apresentando lúmens com diâmetros maiores, principalmente ao redor do sistema vascular do pecíolo (Figuras 1C, 1E) e da nervura central (Figura 1G). Nessa espécie ainda foi observada maior abundância desta estrutura secretora em relação à mesma região de Clusia fockeana (Tabela 1).

THADEO et al. (2009) referiram que os ductos podem estar espalhados no pecíolo, com maior distribuição no parênquima cortical, podendo ocupar algumas vezes a região subepidérmica, corroborando o observado em Clusia fockeana e $C$. hoffmannseggiana.Segundo FRITZ \& SAUKEL (2011), os ductos podem ser observados em quase todos os órgãos da planta, e seu sistema secretor separadamente não pode ser usado para distinguir taxa, mas constitui caráter anatômico adicional importante.

Idioblastos secretores são células individualizadas que possuem conteúdos de aspectos desde 0 amorfo e denso até aqueles formados por gotas volumosas ou não, e cores variando de amarelo esverdeado a castanho (CASTRO et al., 1997). A secreção dentro da planta pode ser transportada por células isoladas, pequenos grupos de células ou tecidos (CUTLER et al., 2011).

Ainda de acordo com FRITZ \& SAUKEL (2011), os ductos podem ser observados em quase todos os órgãos da planta, e seu sistema secretor separadamente não pode ser usado para distinguir taxa, mas constitui caráter anatômico adicional importante.

Ductos secretores, assim como idioblastos, quando avaliados conjuntamente e dependendo da posição que ocupam nos órgãos foliares podem ter valor diagnóstico em nível genérico, uma vez que o estudo realizado por CASTRO et al. (1997) permitiu a identificação de alguns gêneros de Asteraceae. Assim, o padrão de distribuição e a frequência das estruturas secretoras são importantes para fins diagnósticos (BENNICI \& TANI, 2004).

As substâncias armazenadas e/ou secretadas pelos idioblastos e ductos de ambas as espécies são compostos fenólicos (Figuras 2A e 2l), especialmente taninos. 

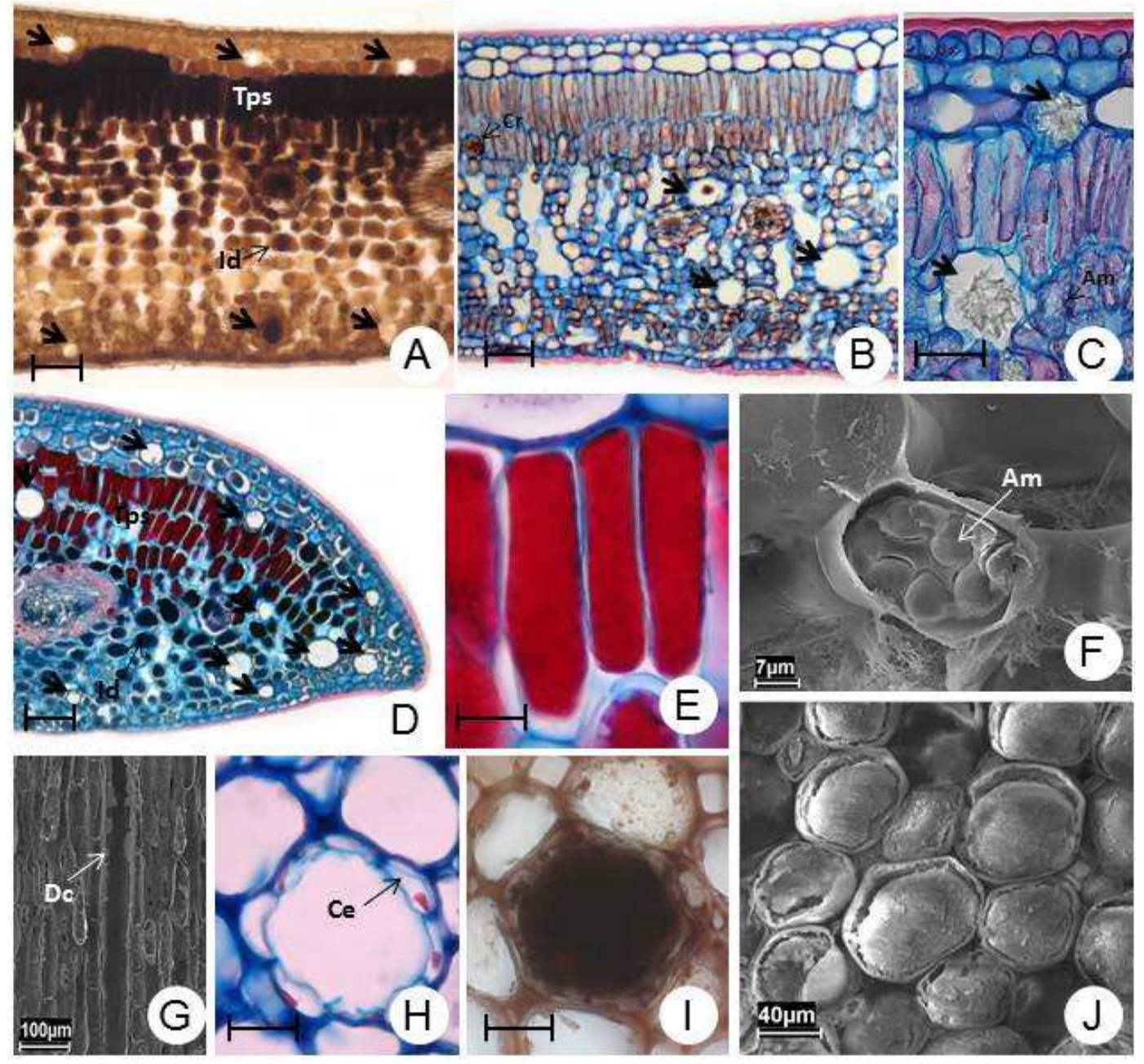

FIGURA 2. Distribuição e anatomia das estruturas secretoras observadas no mesofilo, margem e pecíolo de Clusia fockeana (A, D-F, H) e Clusia hoffmannseggiana (B-C, G, I-J). A. Vista geral do mesofilo, em secção transversal, apresentando ductos encarreirados abaixo das superfícies adaxial e abaxial (setas), notar o tecido paliçádico secretor repleto de substância fenólica. B. Vista geral do mesofilo, notar cristais de oxalato de cálcio e ductos. C. Detalhe dos cristais de oxalato de cálcio. D. Margem exibindo ductos (setas) e o tecido paliçádico secretor. E. Detalhe do tecido paliçádico secretor com conteúdo denso. $\mathrm{F}$ e J. Detalhe do idioblasto com conteúdo denso e grãos de amido $(F)$ e apenas com conteúdo denso (J). G. Detalhe do ducto, em secção longitudinal no pecíolo. H. Ducto, em secção transversal, evidenciando as células epiteliais no pecíolo. I. Ducto, evidenciando compostos fenólicos no interior do lume no pecíolo. $\mathrm{Am}=$ amido, $\mathrm{Ce}=$ células epiteliais, $\mathrm{Dc}=$ Ducto, $\mathrm{Id}=$ idioblasto, $\mathrm{Tps}=$ tecido paliçádico secretor. Escalas: A-B e D $=150 \mu \mathrm{m} ; \mathrm{C}=50 \mu \mathrm{m} ; \mathrm{E}, \mathrm{H} \mathrm{e} \mathrm{I}=20 \mu \mathrm{m} ; \mathrm{G}=100 \mu \mathrm{m} ; \mathrm{F}$ $=7 \mu \mathrm{m} ; \mathrm{J}=40 \mu \mathrm{m}$.

Grãos de amido foram observados nas células dos mesofilos e próximo ao sistema vascular da nervura central de ambas as espécies (Figura 2F). Compostos lipídicos foram constatados apenas na cutícula da camada epidérmica de ambas as 
espécies analisadas. Compostos fenólicos, grãos de amido e idioblastos contendo drusas em abundância na estrutura foliar e pecíolo, são inclusões de grande importância para a caracterização das espécies, pois estão associadas a diversas atividades farmacológicas (SANTA-CECíLIA et al., 2013).

Em geral, os compostos fenólicos estão associados ao mecanismo de adaptação e resistência da planta ao meio ambiente (ROCHA et al., 2011). Já os taninos são eficazes na proteção contra herbivoria por terem um sabor bastante desagradável e serem capazes de desnaturar proteínas (ÁLVAREZ et al., 2008). Cristais de oxalato de cálcio $(\mathrm{CaOx})$ do tipo drusas estão inclusos em células da hipoderme de Clusia hoffmannseggiana (Figuras 2B-C), córtex da nervura central e pecíolo das duas espécies.

Para FRANCESCHI \& NAKATA (2005) a distribuição de cristais dentro da planta é altamente variável entre as espécies. Esta enorme variação na distribuição entre os órgãos, tecidos, tipos de células, e localização no seu interior entre espécies, sugere múltiplas origens independentes de formação destes cristais de $\mathrm{CaOx}$ e suas funções, que incluem a regulação do cálcio, proteção da planta, desintoxicação (por exemplo, metais pesados ou ácido oxálico), o equilíbrio de íons, suporte de tecido/ rigidez da planta e até mesmo de captação de luz e reflexão.

Ainda neste contexto, os cristais de $\mathrm{CaOx}$ podem estar associados com tecidos específicos, por exemplo, na bainha parenquimática ao redor das nervuras, ou idioblastos no mesofilo (CUTLER et al., 2011), corroborando o que foi observado nas espécies em estudo. A presença de lipídios foi evidenciada por FERNADES (2007) e SILVA et al. (2014) na cutícula espessa em ambas as faces das espécies analisadas, além destes estarem distribuídos pelo parênquima e nervura principal, também ocorreram na forma de gotículas de lipídios em células isoladas, fato não observado em Clusia fockeana e C. hoffmannseggiana.

Grãos de amido também foram detectados em todas as espécies estudadas por FERNADES (2007), sendo observados principalmente ao redor do cilindro vascular da nervura principal e no tecido parenquimático. De acordo com SILVA et al. (2014) os grãos de amido exercem função de reserva nessa região.

TABELA 1. Distribuição das estruturas secretoras em folhas de Clusia fockeana e Clusia hoffmannseggiana, ocorrentes na restinga de Crispim, Marapanim, estado do Pará, Brasil.

\begin{tabular}{|c|c|c|c|c|c|c|c|c|c|}
\hline \multirow[t]{2}{*}{ Estruturas secretoras } & \multicolumn{5}{|c|}{$\begin{array}{c}\text { C. } \\
\text { fockeana }\end{array}$} & \multicolumn{4}{|c|}{$\begin{array}{c}\text { C. } \\
\text { hoffmannseggiana } \\
\end{array}$} \\
\hline & & PC & NC & LF & MG & PC & NC & LF & MG \\
\hline Idioblastos & & $x$ & $x$ & $x$ & $\mathrm{x}$ & $x$ & $x$ & $x$ & $\mathrm{x}$ \\
\hline Tecido paliçádico secretor & & $x$ & $x$ & $x$ & $x$ & & & & \\
\hline Ductos na hipoderme & & & & $x$ & $x$ & & & $x$ & $x$ \\
\hline Ductos na porção periférica & & $x$ & $x$ & & & & & & \\
\hline $\begin{array}{l}\text { Abundância de ductos } \\
\text { córtex }\end{array}$ & no & & & & & $x$ & $x$ & & \\
\hline Maior calibre dos ductos & & & & & & $x$ & $x$ & & \\
\hline
\end{tabular}

$\mathrm{PC}=$ Pecíolo, $\mathrm{NC}=$ Nervura central, $\mathrm{LF}=$ Lâmina foliar, $\mathrm{MG}=$ Margem. 
O desenvolvimento dos ductos secretores foi observado no primeiro e segundo nós visíveis de Clusia fockeana e $C$. hoffmannseggiana. As células iniciais dos ductos, em secção transversal, de ambas as espécies analisadas localizam-se no meristema fundamental do mesofilo e nervura central. São células volumosas de paredes delgadas com núcleo evidente e citoplasma denso, as quais sofrem divisões anticlinais que podem ser discernidas pelo arranjo em roseta (Figura $3 A$ ), que à medida que se dividem formam a camada epitelial (Figuras 3B-F). Posteriormente, essas células se expandem gradativamente, promovendo 0 afastamento entre as mesmas, para formar o lume de formato circular (Figuras 3CF), caracterizando o desenvolvimento esquizógeno dos ductos secretores nas duas espécies estudadas. Estes aumentam de calibre à medida que ocorre o seu desenvolvimento.

A diferenciação dos ductos não é sincronizada com os demais tecidos do mesofilo e nervura central. Em todos os estádios de desenvolvimento foram encontrados ductos secretores em atividade. Quanto à formação das estruturas secretoras, estas se desenvolvem por diferentes processos (VENNING, 1948). As divisões sucessivas, na sua maioria, radiais e tangenciais, formam um conjunto de células, que mais tarde constituem as células epiteliais, que delimitam o lume, através de processos esquizógenos e/ou lisígenos (ASCENSÂO, 2007).

Ductos e cavidades esquizógenas formam-se por uma separação de células, resultando em um espaço revestido por células secretoras que compõem o epitélio. Já os lisígenos resultam de uma dissolução (autólise) de células. Nestas estruturas secretoras o produto é formado nas células que, eventualmente, desmembram e liberam o produto para o espaço resultante (EVERT, 2006). Desta forma, em C. fockeana e C. hoffmannseggiana a formação dos ductos ocorreu através da separação de células até a constituição total desta estrutura.

A detecção de secretados exclusivamente no epitélio ou no lume, bem como a sua ocorrência em menor proporção nesses sítios, pode ser indicativo de eventos cíclicos de secreção, especialmente nos casos de ductos esquizógenos maduros (SANT'ANNA-SANTOS et al., 2006). Assim, os estudos ontogênicos de ductos secretores tornam-se necessários como subsídios para discussões taxonômicas, devido a classificação de Clusiaceae ser questionada e/ou mesmo o posicionamento de certos gêneros (CAMPANA et al. 2010). 

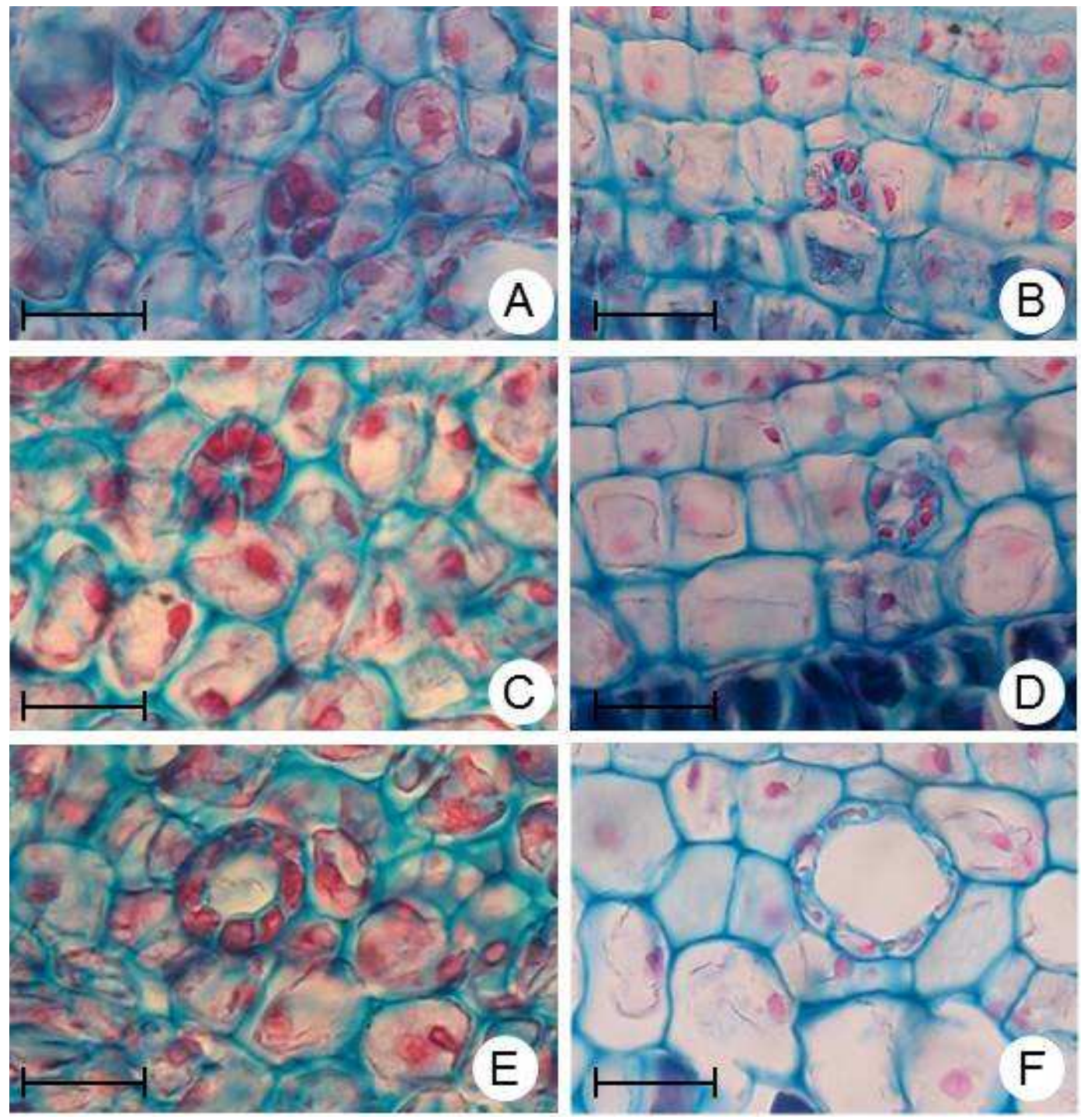

FIGURA 3. Desenvolvimento dos ductos em folhas de Clusia fockeana (B, $D, F)$ e Clusia hoffmannseggiana (A, C, E). A-B. Estágios iniciais de divisão celular. C-F. Formação esquizógena do ducto entre as células secretoras. F. Ducto maduro com células secretoras formando o epitélio em torno do lume. Escalas: A-F= $20 \mu \mathrm{m}$.

\section{CONCLUSÃO}

A distribuição das estruturas secretoras confere valor diagnóstico aos táxons analisados, assim como fornece subsídios para a bioprospecção de seus compostos bioativos, tendo em vista que permitiu identificar as áreas de ocorrência dessas estruturas.

Idioblastos, ductos e tecido paliçádico secretor são as estruturas secretoras presentes nas folhas de Clusia fockeana e C. hoffmannseggiana. Porém, o tecido paliçádico secretor é exclusivo à $C$. fockeana.

Tanino é a principal substância armazenada nos idioblastos e ductos.

Ademais, o desenvolvimento dos ductos secretores no limbo foliar de Clusia fockeana e $C$. hoffmannseggiana ocorre no meristema fundamental do mesofilo e nervura central, através de processo esquizógeno. 


\section{AGRADECIMENTOS}

Ao Laboratório de Anatomia Vegetal da Coordenação de Botânica do Museu Paraense Emílio Goeldi pela infraestrutura concedida e à Caroline Dias pela revisão do Abstract.

\section{REFERÊNCIAS}

ACUÑA, U.M.; JANCOVSKI, N.; KENNELLY, E.J. Polyisoprenylated bezophenones from Clusiaceae: potencial drugs and lead compounds. Current topics in medicinal chemistry, v. 9, p. 1560-1580, 2009.

ÁlVAREZ, R.; ENCINA, A.; PÉREZ HIDALGO, N. Pistacia terebinthus L. leaflets: an anatomical study. Plant Systematics and Evolution, n. 272, p.107-118, 2008.

ANHOLETI, M.C.; PAIVA, S.R.; FIGUEIREDO, M.R.; KAPLAN, M.A.C. Chemosystematic aspects of polyisoprenylated benzophenones from the genus Clusia. Anais da Academia Brasileira de Ciências, v. 87, n. 1, p. 289-301, 2015.

ASCENSÃO, L. Estruturas secretoras em plantas: Uma abordagem morfoanatômica. In: FIGUEIREDO, A.C.; BARROSO, J.G.; PEDRO, L.G. (Eds). Potencialidades e Aplicações das Plantas Aromáticas e Medicinais. $3^{\underline{a}}$ Ed. Faculdade de Ciências da Universidade de Lisboa - Centro de Biotecnologia Vegetal, Lisboa, p.19-28.2007.

BENNICI, A.; TANI, C. Anatomical and ultrastructural study of the secretory cavity development of Citrus sinensis and Citrus limon: evaluation of schizolysigenous ontogeny. Flora, v. 199, n.1, p. 464-475, 2004.

CAMPANA, R.C.; MOURÃO, K.S.M.; MARZINEK, J. Morfoanatomia e ontogênese dos frutos e sementes de Clusia lanceolata Cambess. (Clusiaceae). Acta Scientiarium. Biological Sciences, v. 32, n. 4, p. 437-444, 2010.

CARNEIRO, D.B.; BARBOZA, M.S.L.; MENEZES, M.P. Plantas nativas úteis na Vila dos Pescadores da Reserva Extrativista Marinha Caeté - Taperaçu, Pará, Brasil. Acta Botânica Brasileira, v.24, n. 4, p.1027-1033, 2010.

CASTRO, M.M.; LEITAO-FILHO, H.F.; MONTEIRO, W.R. Utilização de estruturas secretoras na identificação dos gêneros de Asteraceae de uma vegetação de cerrado. Revista Brasileira de Botânica, 1997, v. 20, n. 2, p. 163-174, 1997.

CHAMBERLAIN, C.J. Methods in plant histology. The University of Chicago, Chicago, 1932, $416 \mathrm{p}$.

CICCARELLI, D.; ANDREUCCI, A.C.; PAGNI, A.M. Translucent glands and secretory canals in Hypericum perforatum L. (Hyperiacaceae): morphological, anatomical and histochemical studies during the course of ontogenesis. Annals of Botany, v. 88, p. 637-644, 2001. 
COELHO-FERREIRA, M.G. Notas etnobotânicas sobre plantas medicinais. In: A flora da Resex Chocoaré - Mato Grosso (PA): diversidade e usos. Museu Paraense Emilio Goeldi. Coleção Adolpho Ducke. JARDIM, M.A.G.; ZOGHBI, M.G.B (Orgs.). Belém. p.63-89.2008.

CÔRREA, M.P. Dicionário das plantas úteis do Brasil e das exóticas cultivadas. Ministério da Agricultura, Instituto Brasileiro de Desenvolvimento Florestal. Rio de janeiro, 1984. 687p.

CRONQUIST, A. An integrated system of classification of flowering plants. Columbia University Press, New York, 1981. 1262p.

CRUZ, F.G.; TEIXEIRA, J.S.R. Polyprenylated Benzophenones with a Tricyclo $[4.3 .1 .13,8]$ Undecane Skeleton from Clusia obdeltifolia. Journal of the Brazilian Chemical Society, v.15, n. 4, p. 504-508, 2004.

CUI, J.; HU, W.; CAI, Z.; LIU, Y.; LI, S.; TAO, W.; XIANG, H. New medicinal properties of mangostins: analgesic activity and pharmacological characterization of active ingredients from the fruit hull of Garcinia mangostana L. Pharmacology Biochemistry and Behavior, v. 95, p.166-172, 2010.

CUTLER, D.F.; BOTHA, T.; STEVENSON, D.W. Anatomia vegetal: uma abordagem aplicada. Tradução: MORAES, M. G. Revisão técnica: SANTOS, R. P. Artmed. Porto Alegre. 2011. 304p.

DIAS, V.L.A. 2014. Estruturas secretoras em Medronheiro (Arbutus unedo L.): caracterização morfológica, estrutural e histoquímica e avaliação da atividade proteásica da secreção. 2014, 110f. Mestrado (Biodiversidade e biotecnologia vegetal) - Universidade de Coimbra, Portugal, 2014.

EVERT, R.F. Esau's Plant anatomy: meristems, cells, and tissues of the plant body: their structure, function, and development. 3rd ed. Edição revisada de: Plant anatomy/Katherine Esau. John Wiley \& Sons, Inc., Publication. Hoboken, New Jersey, 2006. 601p.

FAHN, A. Secretory tissues in plants. Academic Press, London, 1979. 302p.

FAHN, A. Secretory tissues in vascular plants. New Phytologist, v.108, p. 229257, 1988.

FERNANDES, S.D.C. Morfologia, anatomia, histoquímica e aspectos fisiológicos da lâmina foliar de espécies de Clusia (Clusiaceae). 2007.148f. Dissertação (Mestrado em Botânica) - Universidade de Brasília, Brasília, DF, 2007.

FERREIRA, R.O.; CARVALHO, M.G. de; SILVA, T.M.S. Ocorrência de biflavonoides em Clusiaceae: aspectos químicos e farmacológicos. Química Nova, v. 35, n.11, p. 2271-2277, 2012. 
FONSECA, C.N.; LISBOA, P.L.B.; URBINATI, C.V. A Xiloteca (Coleção Walter A. Egler) do Museu Paraense Emílio Goeldi. Boletim Museu Paraense Emílio Goeldi. Ciências Naturais, v.1, n.1, p. 65-140, 2005.

FRANCESCHI, V.R.; NAKATA, P.A. Calcium Oxalate in Plants: Formation and Function. Annual Review of Plant Biology, v. 56, p. 41-71, 2005.

FRITZ, E.; SAUKEL, J. Secretory structures of subterranean organs of some species of the Cardueae, and their diagnostic value. Acta Biológica Cracoviensia. Série Botânica, v. 53, n. 1, p.63-73, 2011.

GASPAROTTO-JÚNIOR, A.; BRENZAN, M.A.; PILOTO, I.C.; CORTEZ, D.A.G.; NAKAMURA, C.V.; FILHO, B.P.D.; FILHO, E.R.; FERREIRA, A.G. Estudo fitoquímico e avaliação da atividade moluscicida do Calophyllum brasiliense Camb. (Clusiaceae), Química Nova, v. 28, n. 4, 2005a.

GASPAROTTO-JÚNIOR, A.; FERREIRA, I.C.P.; NAKAMURA, C.V.; FILHO, B.P.D.; JACOMASSI, E.; YOUNG, M.C.M.; CORTEZ, D.A.G. Estudo morfoanatômico das folhas e caule de Calophyllum brasiliense (Clusiaceae): uma contribuição ao estudo farmacognóstico da droga vegetal. Acta Farmaceutica Bonaerense, v. 24, p. 371$76,2005 b$.

GERLACH, G. Botanische Mikrotechnik: eineeinfuhrung. Georg Thieme. Stuttgard. 1969, $344 \mathrm{p}$.

HUERTA-REYES, M.; BASUALDO, M. Del C.; LOZADA, L.; JIMENEZ-ESTRADA, SOLER, C.; REYES-CHILPA, R. HIV - 1 inhibition by extracts of Clusiaceae species from Mexico. Biological \& Pharmaceutical Bulletin, v. 27, n. 6, p. 916-920, 2004.

JARDIM, M.A.G.; SILVA, J.C.; COSTA-NETO, S.V. Fitoterapia popular e metabólitos secundários de espécies vegetais da llha de Algodoal, município de Maracanã, estado do Pará, Brasil - Resultados preliminares. Revista Brasileira de Farmacologia. p. 117-118.2005.

JOHANSEN, D.A. Plant microtechnique. McGraw-Hill Book, New York. 1940, 523p.

JOLY, A.B. Botânica: introdução à taxonomia vegetal. $12^{\mathrm{a}}$ ed., Editora Nacional, São Paulo. 1998, 778p.

LOKVAN, J.; BRADDOCK, J.F. Anti-bacterial function in the sexually dimorphic pollinator rewards of Clusia grandiflora (Clusiaceae). Oecologia, v.119, p. 534-540, 1999.

LOKVAN, J.; BRADDOCK, J.F.; REICHARDT, P.B.; CLAUSEN, T.P. Two polyisoprenilated benzophenone from trunk latex of Clusia grandiflora (Clusiaceae). Phytochemistry, v.55, p.29-34, 2000.

LÜTTGE, U. Structure and function of plant glands. Annual Review of Plant Physiology, v. 22, p. 23-44, 1971. 
MACE, M.E.; HOWELL, C.R. Histochemistry and identification of condensed tannin precursors in roots of cotton seedlings. Canadian Journal of Botany, v.52, p. 24232426, 1974.

MARTI, G.; EPARVIER, V.; MORETTI, C.; PRADO, S.; GRELLIER, P.; HUE, N.; THOISON, O.; DELPECH,B.; GUÉRITTE, F.; LITAUDON, M. Antiplasmodial benzophenone derivatives from the root barks of Symphonia globulifera (Clusiaceae). Phytochemistry, v.71, p. 964-974, 2010.

METCALF, C.R.; CHALK, L. Anatomy of the Dicotyledons - leaves, stem and wood in relation to taxonomy with notes on economic uses. Clarendon Press: Oxford. 1950, 1500p.

NOLDIN, V.F.; ISAIAS, D.F.; FILHO, V.C. Gênero Calophyllum: importância química e farmacológica. Quimica Nova, v. 29, n. 3, p. 549-554, 2006.

OTUKI, M.F.; BERNARDI, C.A.; PRUDENTE, A.S.; LASKOSKY, K.; GOMIG, F.; HORINOUCHI, C.D.S.; GUIMARÃES, C.L.; FERREIRA, J.; DELLE-MONACHE, F.; CECHINEL-FILHO, V.; CABRINI, D.A. Garcinia gardneriana (Planchon \& Triana) Zappi. (Clusiaceae) as a Topical Anti-inflammatory Alternative for Cutaneous Inflammation. Basic \& Clinical Pharmacology \&Toxicology, n.109, p.56-62, 2011.

PAULA, J.E. Notas sobre a anatomia de Clusia grandiflora Splitg. (Guttiferae). Instituto Nacional de Pesquisas da Amazônia, Botânica, n. 22, p.1-24, 1966.

PEDRAZA-CHAVERRI; J. CÁRDENAS-RODRÍGUEZ, N; OROZCO-IBARRA, M.; PÉREZ-ROJAS, J.M. Medicinal properties of mangosteen (Garcinia mangostana). Food and Chemical Toxicology, n. 46, p. 3227-3239, 2008.

PINHEIRO, L.; CORTEZ, D.A.G.; VIDOTTI, G.J.; YOUNG, M.C.M.; FERREIRA, A.G. Estudo fitoquímico e avaliação da atividade moluscicida da Kielmeyera variabilis Mart (Clusiaceae). Química Nova, v. 26, n. 2, p. 157-160, 2003.

PRETTO, J.B.; CECHINEL-FILHO, V.; NOLDIN, V.F.; SARTORI, M.R.; ISAIAS, D.E.; CRUZ, A.B. Antimicrobial activity of fractions and compounds from Calophyllum brasiliense (Clusiaceae/Guttiferae). Zeitschriftfür Naturforschung, v. 59, n. 9-10, p. 657-662. 2004.

RÊGO, M.S.C. 2012. Anatomia foliar de duas espécies de Clusia L. (Clusiaceae Lindley): estratégias adaptativas para a restinga do Crispim. 2012, 82f. Dissertação (Mestrado em Ciências Biológicas) - Universidade Federal Rural da Amazônia/ Museu Paraense Emílio Goeldi, Belém, PA, 2012.

REYES-CHILPA, R.; HUERTA-REYES, M.E. Compuestos naturales de plantas de lafamiliaClusiaceae: inhibidoresdel vírus de inmunodeficiencia humana tipo1. Interciência, v. 34, n. 6, p. 385-392, 2009.

RIBEIRO, J.E.L.S.; HOPKINS, M.J.G.; VICENTINI, A.; SOTHERS, C. A.; COSTA, M. A.S.; BRITO J.M.; SOUZA, M.A.D.; MARTINS, L.H.P.; LOHMANN, L.G.; ASSUNÇÃO, P.A.C.L.; PEREIRA, E.C.; SILVA, C.F.; MESQUITA, M.R.; 
PROCÓPIO, L.C. Flora da reserva Ducke: Guia de identificação das plantas vasculares de uma floresta de terra-firme na Amazônia Central. INPA, Manaus. 1999. 793p.

RIBEIRO, P.R.; FERRAZ, C.G.; GUEDES, M.L.S.; MARTINS, D.; CRUZ, F.G. A new biphenyl and antimicrobial activity of extracts and compounds from Clusia burlemarxii. Fitoterapia, v. 82, n. 8, p. 1237-1240, 2011.

ROCHA, W.S.; LOPES, R.M.; SILVA, D.B.; VIEIRA, R.V.; SILVA, J.P.; AGOSTINICOSTA, T.S. Compostos fenólicos totais e taninos condensados em frutas nativas do cerrado. Revista Brasileira de Fruticultura. v. 33, n. 4, p. 1215-1221, 2011.

ROCHA, D.I.; SILVA, L.C.; PEREIRA, E.G.; SANT'ANNA-SANTOS, B.F.; GONTIJO, E.R.; OLIVA, M.A. Early detection of injuries in leaves of Clusia hilarianas Chltdl. (Clusiaceae) caused by particulate deposition of iron. Revista Árvore, v. 38, n. 3, p. 423-432, 2014.

SANTA-CECÍLIA, F.V.; ABREU, F.A.; DA SILVA, M.A.; DE CASTRO, E.M.; DOS SANTOS, M.H. Estudo farmacobotânico das folhas de Garcinia brasiliensis Mart. (Clusiaceae). Revista Brasileira de Plantas Medicinais, v. 15, n. 3, p. 397-404, 2013.

SANT'ANNA-SANTOS, B.F.; THADEO, M.; MEIRA, R.M.S.A.; ASCENSÃO, L. Anatomia e histoquímica das estruturas secretoras do caule de Spondias dulcis Forst. F. (Anacardiaceae). Revista Árvore, v. 30, p. 481-489, 2006.

SCHNEIDER, S.Z. 1985. Anatomia foliar de Clusia hilariana Schltdl. e Clusia spiritu santensis (Guttiferae), ocorrentes no Estado do Espírito Santo. 1985, 142p. Dissertação (Mestrado em Ciências biológicas - Botânica), Museu Nacional/Universidade Federal do Rio de Janeiro, RJ, 1985.

SILVA, L.C.; OLIVA, M.A.; AZEVEDO, A.A.; ARAÚJO, J.M.; AGUIAR, R. M. Micromorphological and anatomical alterations caused by simulated acid rain in restinga plants: Eugenia uniflora and Clusia hilariana, Water, Air, and Soil Pollution, v.168, p. 129-143, 2005.

SILVA, C.R.A.; LEITE, K.R.B.; FERREIRA, L.M. dos S.L.; SILVA, M.S.; SILVA, L.B. Influência da altitude na plasticidade foliar de Clusia obdeltifolia Bittrich (Clusiaceae). Revista Nordestina de Biologia, v. 23, p. 29-48, 2014.

STEVENS, P. F. Clusiaceae (Guttiferae). In: Kubitzki K. (ed.). The families and genera of vascular plants. Springer. Verlag Berlin Heidelberg. p.48-66. 2007.

THADEO, M.; MEIRA, R.M.S.A.; AZEVEDO, A.A.; ARAÚJO, J.M. Anatomia e histoquímica das estruturas secretoras da folha de Casearia decandra Jacq. (Salicaceae). Revista Brasileira de Botânica, v. 32, n. 2, p. 329-338, 2009.

VENNING, F. D. The ontogeny of the laticiferous canals in the Anacardiaceae. American Journal of Botany, v. 35, p. 637-644, 1948. 
VILHENA-POTIGUARA, R.C.; AGUIAR-DIAS, A.C.A.; KIKUCHI, T.Y.S.; SANTOS, A.C.F.; SILVA, R.J.F. Estruturas secretoras em cipó-d'alho (Mansoa standleyi (Steyerm.) A. H. Gentry, Bignoniaceae): ocorrência e morfologia. Acta Amazônica, v. 42, n. 3, p. 321-328, 2012. 